\title{
MARTÍ: NACIÓN, SUJETO E IDENTIDAD. EN UNA RELECTURA DE NUESTRA AMÉRICA ${ }^{1}$
}

Martí: Nation, subject and identity upon rereading Nuestra América

Marco Chandia Araya*

Resumen

En el actual clima de acechantes cuestionamientos sobre la identidad regional, suelen tener recepción versiones cuando no ahistóricas o esencialistas, deterministas o simplistas que lo que hacen es reducir la noción arrinconándola en categorías que poco o nada aportan a la autocomprensión de nuestros pueblos. De modo que resulta pertinente volver sobre una mirada en que la identidad debe ser concebida como un fenómeno social complejo, conflictuado y relacional en constante reconstrucción. Nuestra América, en este sentido, sigue siendo un texto fundamental porque no solo permite comprender la idea de nación moderna que propone el cubano, sino también el modo de construirla. Un proyecto sociocultural inconcluso y que lo será solo si acepta la diferencia como constructo base de nuestra heterogénea realidad.

Palabras clave: Nación, Sujeto, Cultura, Identidad, América Latina, José Martí.

Abstract

In the current climate of pressing questions about regional identity, there tends to be, if not ahistorical or essentialist versions, at least determinist or simplistic ones that only reduce the notion cornering it into categories that contribute little or nothing to the understanding of our peoples. Therefore, it is pertinent to turn our eyes toward a vision of identity that should be conceived as a complex, conflictive, and relational social phenomena in constant reconstruction. "Nuestra América", in this sense, continues to be a fundamental text since it not only permits us to understand the idea of the modern nation proposed by the Cuban, but also the way in which it must be build. This is an inconclusive sociocultural project which will only be finished if difference is accepted as a basic building block of our heterogenous reality.

Key words: Nation, Subject, Culture, Identity, Latin America, José Martí.

Esa de racista está siendo una palabra confusa, y hay que ponerla en claro. El hombre no tiene ningún derecho especial porque pertenezca a una raza $u$ otra: digase hombre, y ya se dicen todos los derechos. El

\footnotetext{
${ }^{1}$ El artículo forma parte del marco teórico fundamental de la tesis "Hacia una poética de la frontera urbana, porteña y popular. Imaginarios chileno-peruanos, de los ojos imperiales a nuestra propia expresión" (2012), del Doctorado en Literatura chilena e hispanoamericana de la Universidad de Chile, y cierra la segunda parte enfocada al problema de la cultura/identidad regional, denominada "América Latina y su autoconstrucción. Nuestroamericanismo".
} 
negro, por negro, no es inferior ni superior a ningún otro hombre: peca por redundante el blanco que dice: 'mi raza': peca por redundante el negro que dice: 'mi raza'. Todo lo que divide a los hombres, todo lo que los especifica, aparta o acorrala, es un pecado contra la humanidad [...] Hombre es más que blanco, más que mulato, más que negro.

José Martí

Hemos de reconocer, en principio, que no somos europeos ni estadounidenses, y que por no ser europeos ni estadounidenses no podemos pretender pensar, sentir, imaginar, en una frase: vivir como ellos. Aquí entra en juego una primera cuestión clave que recoge Grínor Rojo, el convencimiento en Martí que América Latina constituye un pueblo distinto: "un pueblo que se puede comunicar con otros pueblos sin ninguna duda, que puede oír lo que esos otros pueblos le dicen, entrar en tratos con ellos y aun aprender de ellos, pero desde un repertorio de opciones que no debiera comprometer jamás lo que forma parte de nuestra "naturaleza"' [su subrayado] (Clásicos latinoamericanos, 218). Entonces, como somos distintos pero no tanto como para no relacionarnos con otros, con quienes incluso podemos crecer, siempre y cuando mantengamos nuestra 'naturaleza', aquello irreductible, es que tenemos, pues, que vivir como nosotros. Y para eso debemos reconocer que nuestra historia ni se ha hecho sin influjos, ni se ha hecho de puros influjos. Nuestra historia, en consecuencia, nuestra cultura y, en lo mismo, nuestra identidad, todas, se han configurado como una lucha entre estos dos polos, lo externo y lo interno, lo local y lo universal, lo propio y lo ajeno, lo occidental y lo tradicional; entre blancos, indios y negros. Ha sido un largo proceso donde ha primado una relación dialéctica, de encuentros y desencuentros históricos. Pero la dificultad esencial es la que plantea José Martí. Haber sido, primero, descubiertos por Europa, luego, colonia por tres siglos y, en ella, tener que adoptar una lengua, un credo, una cosmovisión que no era nuestra sino de ellos.

Todo esto hace que en la región haya predominado siempre una tendencia a valorar lo de afuera por sobre lo de adentro, lo exógeno por encima de lo endógeno, y, a veces, también, al revés: negar todo influjo para asumir como único camino legítimo lo autóctono. Sin embargo, insistimos, ha primado siempre la primera tendencia. Un impulso imitativo, reproductor, carente de originalidad, que quiere trasplantar Europa y su cultura: occidentalizar este mundo, negando lo que tenemos. Esa es la principal dificultad y desde donde Martí nos invita a reflexionar, y a actuar, para que no seamos copia, ni para que tampoco estemos ausentes del banquete de la civilización, ya que la modernidad, si bien es innegable, no es un fin en sí misma, ni un destino. Es, por el contrario, la modernidad, un proyecto.

Y al ser un proyecto, el rol de los lectores de Martí se activa, pues nos insta, nos interpela, a actuar y a involucrarnos en el proceso. El camino, la trayectoria, el

${ }^{2}$ Martí, J., Mi raza, tomo III, 2002, pp. 205-206. 
cómo, pasan a ser, desde entonces, los rasgos principales entre Latinoamérica y la modernidad. Eso es lo que nos debe preocupar ahora a nosotros, del mismo modo como preocupó a Martí y a sus coetáneos. Intelectuales y pensadores, como el cubano que vivió en el monstruo y le conoció sus entrañas. Nosotros, creemos, tenemos que leer Nuestra América en este sentido. En un sentido histórico, propio, de nosotros mismos, y como un proyecto de vida latinoamericano que no ha concluido aún. Porque si ayer eran el parnasianismo, el falso refinamiento, las máscaras y la exportación ciega, y por tanto, el desprecio al indígena, su economía, sus creencias, su cultura, su identidad, hoy el problema es la intrascendencia, la insustancialidad, lo superfluo, el relativismo, el consumo masivo, la pérdida de valores fundamentales. Como dice Rojo, Martí se ha dado cuenta "que el peligro ha dejado ya de ser una simple amenaza" (Clásicos latinoamericanos, 201). Si a fines del siglo XIX nos alertaba contra el capitalismo yanquee, ese gigante de botas de siete leguas, hoy nos ilumina el camino mediante su obra contra el neoliberalismo, las tendencias posmodernas, el desarraigo, la falta de identidad, la desterritorialización, el desprecio por el otro, la violencia, el egoísmo, en fin, todo lo que hoy nos aleja del hombre. Esta es nuestra realidad y con ella debemos lidiar. Pero no lo podemos hacer solos ni en estas circunstancias, necesitamos crear las condiciones para que impere una forma de convivencia en la que los seres humanos se pongan a la altura de esta meta superior, descubrir su capacidad de ser lo que deben ser. Agrega Rojo a esto que en Martí hay "un ser y un poder ser del hombre, [...] un ser uno uno mismo, y también un potencial del ser del hombre, la posibilidad de ser uno más de lo que es, pero ello [...] desde el fondo de uno mismo". Para el crítico chileno este potencial no se da sin libertad ni sin voluntad, las que provee la historia y que finalmente es a lo más alto que como hombres podemos aspirar (217). Esto a nosotros nos alienta porque reafirma la utopía y esa fe de Henríquez Ureña en "ser mejor de lo que es y socialmente vivir mejor de como vive" (6-7). Todo ello, espontánea, inmediata e irremediablemente, hace contacto con la dimensión anímica que mueve cualquier trabajo cuyo fin sea proponer una mirada alternativa respecto de la historia de nuestra cultura-identidad latinaomericana. Renueva las fuerzas y pone a la vista el porvenir.

Para eso resulta pertinente revisar el conflicto de nuestra modernidad a la luz de Nuestra América (1891). Al hacernos cargo de una lectura interpretativa del ensayo martiano, asumimos, desde ya, el compromiso que está implícito en su obra. Creemos que lo que Martí nos exige, a nosotros, intelectuales latinoamericanos actuales, sujetos críticos de una sociedad capitalista que niega cada vez más al hombre y contra lo que - aparentemente - no habría mucho por hacer, es nada menos que hacernos cargo del proyecto que él propone. Proyecto que no es otro que construir —o reconstruir después de más de cien años planteado el propósito-, a partir de toda la experiencia universal viva, nuestra propia realidad como nación en constante transformación, como un todo que se hace y rehace desde el cotidiano, y 
como una forma de ser capaz de proponer una cosmovisión distinta al paradigma moderno occidental, desde una realidad, un sujeto y una identidad que le son propios.

Simón Bolívar es significativo al respecto, pues es quien, ante el caos anárquico o la tiranía imperial, suscitada al albor del clima posindependentista, no ve otra salida que la integración regional, velada por el sistema inglés, para conseguir una libertad que luego hay que aprender a usarla. Martí, como tal, contribuirá también con una propuesta que evite el mal mayor, y al cabo inminente, pero también, y al mismo tiempo, que la salida reporte una ganancia significativa en materia humana. El mal mayor es el imperialismo norteamericano y la consecuente pérdida de identidad, $\mathrm{y}$, el avance, que la libertad que protegió Bolívar llegue por fin al pueblo latinoamericano. Rojo dice que esto está en Nuestra América, y que se presenta por medio de una motivación (estado de alerta, agregamos nosotros, porque advierte que el gigante ya está actuando) y dos desarrollos. El primero - igual que Bolívar, otra vez-, es el llamado a la unidad, el segundo, a que la unidad sea en conciencia. La unidad en Martí sigue siendo la misma de Bolívar, y qué otra puede ser, si las diferencias pueden nivelarse por los años que separan los anuncios, setenta y seis nada menos. El cubano grafica la unidad en que "Ya no podemos ser el pueblo de hojas, que vive en el aire, con la copa cargada de flor, restallando o zumbando, según la acaricie el capricho de la luz, o la tundan y talen las tempestades: ¡los árboles se han de poner en fila, para que no pase el gigante de las siete leguas! Es la hora del recuento, y de la marcha unida, y hemos de andar en cuadro apretado, como la plata en las raíces de los Andes" (Martí, 480).

La no dependencia de España o de los Estados Unidos o de cualquier otra hegemonía la garantiza solo la unidad. Sabemos que Martí está pensando en la embestida del capitalismo norteamericano y la manera de hacerle frente, desafío desde ya complejo. Por eso estamos ante una unidad cuyo sentido no se logra si no es - y aquí el segundo tema del desarrollo - como "el producto de un proceso previo e interno", es decir, de un ejercicio de autoconciencia en el que participen todas las naciones. Una toma de conciencia, agrega Rojo, "por parte de los pueblos que se hallan involucrados en los avatares de aquel fin de siglo, de la verdad de su ser particular, esto es de su 'naturaleza' nacional y regional, y en la proyección de una conducta política que sea consecuente con ello" [su subrayado] (Clásicos latinoamericanos, 220). La unidad requiere conocer/se, en y con el vecino. Apunta a un sujeto que debe forjarse ahora histórica y relacionalmente, con la experiencia recogida a lo largo de todos los años de vida independiente. Aquí se debe terminar conformando la identidad de un individuo que entonces no había logrado - según Bolívar- el grado de autorreflexión que requería para hacerse cargo del magno proyecto moderno. Y no porque no quiso o no debía, sino porque la elite que se

\footnotetext{
${ }^{3}$ Resaltamos la sutileza con que Julio Ramos trabaja la figura del árbol, lo telúrico, la raíces, la madre América, el sentido de la naturaleza primigenia arraigada a lo más bajo y elemental en contraposición con la metáfora elevada y en movimiento del gigante (Ramos 294).
} 
arrogó a su haber la conducción de un Estado, que no era tan moderno ni tan modernizado como decía, no le dejó. Impidió con toda suerte de coerciones que creciera por sí mismo. Fue cuando le creó una nación y le empujó luego a participar de ella, exigiéndole ser parte de un artificio incómodo por espurio, negador de su diferencia, represivo y desconfiable. En instancias como estas, que no promuevan la autorreflexión, no hay verdadera identidad y por tanto tampoco una nación particular y concreta, y menos entonces una América Latina íntegra que pudiera hacerle frente a la embestida capitalista. Todo eso, según podemos entender nosotros, es lo que tiene en mente Martí hacia fines del siglo XIX y que ensaya en Nuestra América.

Para entender mejor esto vamos a desplegar los dos desarrollos que encuentra Rojo en la obra martiana. El primero, decíamos, es el sentido de unidad que Martí retoma de las ideas de Bolívar, el que actualiza incorporándole un ingrediente más: el autoconocimiento, que es a su vez el segundo tema del desarrollo. Sin embargo para Rojo la cuestión esta del autoconocimiento es solo el punto de partida que conduce al problema de fondo que plantea Martí. Porque estaría compuesta, dice él, de tres "esfuerzos" para llegar a ella. O sea, para que la unidad de todas y cada una de las naciones sea integral se requiere de un grado de conciencia que se va a lograr solo si se llevan a cabo estos tres esfuerzos interpretativos. Primera cuestión, reconocer que América Latina está hecha a base de un desajuste inicial que se da entre la estructura del Estado y su contenido. Segundo, tener claro que sin libertad ningún logro es real. Y tercero, denunciar que ha habido una exclusión de clase que se debe combatir con una cultura integradora y solidaria. Vamos a referimos a cada paso en particular, los que en su conjunto debieran entregarnos las claves para una efectiva y pertinente lectura de este magistral ensayo.

En cuanto al desajuste ya hemos dicho que es un problema que atraviesa toda la primera época moderna, y que se mantendrá incluso hasta hoy. Es quizá uno de los conflictos mayores que definen y afectan nuestra particular modernidad. Son recurrentes los términos de desencuentro, inestabilidad o desequilibrio para referirse al tipo de modernidad latinoamericana. Aparte de lo ya dicho, insistamos en que hay una incoherencia, una grave incoherencia entre la realidad y los símbolos, es decir, entre las ideas que sustentan la nación y la nación misma. Para un buen gobierno debe haber entre ambos un justo equilibrio y esto se logra solo conociendo aquello que se gobierna, de lo contrario no se podrá gobernar, o, lo que es peor, se gobernará mal. A propósito, dice el prócer cubano: "El gobierno ha de nacer del país. El espíritu del gobierno ha de ser el del país. La forma de gobierno ha de avenirse a la constitución propia del país. El gobierno no es más que el equilibrio de los elementos naturales del país" (Martí, 482).

Aquí Rojo repara en algo medular y que nosotros podemos dar cuenta cuando estudiamos la trayectoria chilena y denunciamos la disonancia de origen que hay entre el Estado y la nación, representada por la "escandalosa inadecuación de las 
estructuras estatales respecto de los contenidos nacionales"4. Esta es la madre de todos los males: haber pasado por alto el contenido, lo real y lo particular, o sea, no haber tomado en cuenta a la comunidad que es la nación ${ }^{5}$. En tanto, la elite mantuvo su carácter despreciativo. Por otra parte, con esto no se agota la cuestión del desajuste porque hasta aquí solo hemos dado con el problema. Se trata ahora, de acuerdo a la lectura que hacemos de Rojo, de desarmar todo ese aparataje simbólico que no ha hecho más que sostener la idea de una falsa nación, y que por falsa niega al sujeto nacional, para crear otro, ahora desde él mismo, y partir del reconocimiento de un sujeto que no es ese "espantajo" homogéneo y armónico que por interés y acomodo creó, promovió e instaló la oligarquía en el imaginario nacional. Por consiguiente, como no hay sujeto que sirva porque el que hay es falso, lo que viene se adivina: habrá que crearlo. ¿Y desde dónde y cómo se crea? Pues desde la reapropiación de la experiencia encarnada en el pueblo real, y con originalidad.

Aquí se yergue un sujeto que no dejará nada fuera, llevando en su recorrido autoconstructivo el sello indeleble de su peso histórico. Un acto de creación indispensable que requiere, como advierte el insigne poeta cubano, saber con qué elementos está hecho. Dice Martí, atacando a quienes quieren hacer creer que para ser original basta con reciclar:

La incapacidad no está en el país naciente, que pide formas que se le acomoden y grandeza útil, sino en los que quieren regir pueblos originales, de composición singular y violenta, con leyes heredadas de cuatro siglos de práctica libre en los Estados Unidos, de diecinueve siglos de monarquía en Francia. Con un decreto de Hamilton no se le para la pechada al potro del llanero. Con una frase de Sieyès no se desestanca la sangre cuajada de la raza india. A lo que es, allí donde se gobierna, hay que atender para gobernar bien; y el buen gobernante en América no es el que sabe cómo se gobierna el alemán o el francés, sino el que sabe con qué elementos está hecho su país (Martí, 481-482).

\footnotetext{
${ }^{4}$ Lo que está detrás de estos es la disputa que se da entre los conceptos de estabilidad y legitimidad. Si bien al Estado chileno se le puede atribuir estabilidad, ya que por medio de un poder firme y centralizado hizo de Chile un país estable, sólido y consolidado, no se le puede otorgar en cambio el voto de la legitimidad. El Estado no es legítimo aunque sí estable. $O$, más preciso aún: la ilegitimidad es el costo que debió pagar el Estado, por ser estable. No por condición sino por opción. La opción de una elite con intereses económicos. "La 'estabilidad' [...] es una cualidad de pertenencia sistemática, y la 'legitimidad' (que no es una mera cualidad subjetiva sino el derecho y el poder de la soberanía) una decisión ciudadana. Pero, históricamente, la 'estabilidad' ha sofocado y enterrado a la 'legitimidad'. Tanto, que la historia de aquella es pública, oficial y visible, y la de esta oscura y soterrada, que solo se hace visible cuando 'revienta' sobre la superficie de aquella. Por lo mismo, cuando el historiador se sitúa para trabajar a ras de ciudadano, lo hace como un arqueólogo: desenterrando sujetos y hechos ocultos, devaluados u olvidados. Casi subversivamente" [marcas suyas]. (Salazar y Pinto, 14 y ss.).

${ }^{5}$ Los únicos que sí lo hicieron -aunque mejor que no lo hubiesen hecho- fueron los tiranos, los caudillos, los Páez, los Santa Cruz, los Rosas, "porque eran congruentes con la verdad de los habitantes del país respectivo" (Rojo, 221).
} 


\section{CREAR. EL INGREDIENTE INDISPENSABLE}

En la construcción del buen gobierno, el carácter incondicional de la originalidad, surgido de un sublime acto creativo, sumado al material con que se hace, "su levadura", es el rasgo distintivo, la "virtud superior" sobre la que descansará la patria nueva. No se puede crear a partir de lo ajeno, de lo heredado, de lo exótico. Aunque todo o casi todo siga siendo de Europa, estos no dan con "la clave del enigma hispanoamericano".

Las levitas son todavía de Francia, pero el pensamiento empieza a ser de América. Los jóvenes de América se ponen la camisa al codo, hunden las manos en la masa, y la levantan con la levadura de su sudor. Entienden que se imita demasiado, y que la salvación está en crear. Crear es la palabra de pase de esta generación. El vino, de plátano; y si sale agrio, jes nuestro vino! Se entiende que las formas de gobierno de un país han de acomodarse a sus elementos naturales; que las ideas absolutas, para no caer por un yerro de forma, han de ponerse en formas relativas; que la libertad, para ser viable, tiene que ser sincera y plena; que si la república no abre los brazos a todos y adelanta con todos, muere la república [...]. (Martí, 485).

Martí sabe que el futuro de América Latina es la modernidad, atisba su advenimiento, ese tiempo nuevo del que no vale ocultarse sino enfrentarlo con la mejor arma que como sociedad podemos contar: la originalidad. Junto con criticar el liberalismo burgués, ese capitalismo salvaje que avanzaba a pasos agigantados, y que bien pudo conocer en la bullente Nueva York, donde estaba relegado (quizá sea lo único menos malo que tenga el exilio), nos exhorta, por medio de los líderes de entonces, a crear una nación que no sea la reproducción del modelo europeo, sino la peculiaridad de lo nuestro. Para la crítica seria, aparece aquí, como en ninguna otra, ni antes ni después, la diferencia. Concebir que este grupo de naciones son diferentes, y que por ser diferentes deben crear a partir de lo que son, crear desde lo propio, y no asimilar a ciegas los modelos. Erradicar la tendencia mimética para crear desde nuestra propia realidad es la salida que ofrece Martí.

En este sentido, el ensayo martiano contiene en grado importante las claves para entender el proceso transculturador que décadas después, a mediados del siglo $\mathrm{XX}$, va a venir a ocupar un lugar destacado en la discusión sobre la modernidad latinoamericana. Sin duda, la metáfora clave para comprender esta relación (que Fernando Ortiz plantea como transculturación), es la que dice: “...injértese en nuestras repúblicas el mundo; pero el tronco ha de ser el de nuestras repúblicas" (Martí, 483). Según Rojo, quien revisa el ensayo que Subercaseaux escribiera a propósito de "Nuestra América", habría una tensión latente entre modernización y cultura, una tensión que "recorre todo el texto y es en cierta medida el eje temático del 


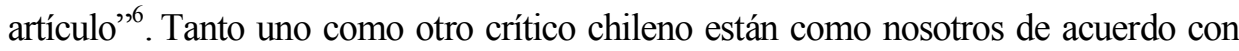
que Martí, con esa figura retórica, "estaría aceptando que en el árbol latinoamericano se introduzca una rama ajena, pero a condición de que se salve "el tronco"', es decir, la cultura [subrayado suyo] (Las armas de las letras, 101) ${ }^{7}$. Ahora, en el escenario actual, la visa que Martí le da a lo extranjero parece un acto del todo ingenuo y, por tanto, nos pone frente a un Martí anacrónico, aunque la intromisión foránea se iba a dar sí o sí. Pero no es así. Sabía que era inevitable y hasta necesario el influjo, como sabía que era por completo evitable y por supuesto preocupante la pérdida de nuestra identidad cultural. Es más, nos consta que Martí reconocía y hasta valoraba la interpenetración entre ambas culturas. Sin embargo, lo que más le preocupaba era la forma cómo se estaba llevando a cabo esa transculturación. Dice Rojo, citando a Subercaseaux: "Martí evidencia una postura nítidamente evolucionista y organicista. No es partidario de una modernización abrupta, impuesta o unilateral; sí lo es en cambio de un proceso lento e integrado, que se lleve a cabo con espíritu creativo y crítico y atendiendo siempre a los factores que proporcionan la realidad de cada país" (Las armas de las letras, 102).

Ahora, una cosa es aceptar la originalidad como única salida plausible hacia una auténtica modernidad y otra distinta, y todavía más compleja, es afirmar que América Latina por ser parte de una misma y única historia, es homogénea. Este es un problema crucial dentro de nuestra cultura. Latinoamérica no solo debe construirse desde el tronco, sino que debe, sobre todo, ser capaz de unir una totalidad que es profundamente heterogénea ${ }^{9}$. El cometido entonces es doble. Porque no basta, para que el proyecto martiano tenga éxito, la necesaria condición creativa, ya que estamos hablando de crear una nación, una patria, una comunidad acosada por influjos de todo tipo. Se requiere, además, que esta creación sea integradora, que no deje a nadie fuera. Sobre todo cuando, histórica y paradojalmente, como se dijo, lo que ha quedado fuera ha sido, ni más ni menos, el componente esencial de lo que se quiere levantar: esto es la enorme masa de población múltiple y diversa. Más aún, tampoco es una integración pasiva, un llamado a los que no estuvieron para que estén, intentando así resarcir la exclusión. La cuestión está en que esos que no estuvieron estarán ahora como titulares, es decir, como parte constitutiva en que cada uno es nación. Ahora, cuando Martí apela a esta diversidad está diciendo que este componente identitario no es homogéneo sino heterogéneo. O sea, un elemento integrador que sin negar las

\footnotetext{
${ }^{6}$ La alusión al escrito de Subercaseaux: Chile, ¿un país moderno? (94).

7 "Martí y la identidad" (Las armas de las letra, 101-116).

${ }^{8}$ Con esto se estaba echando encima no solo a aquellos liberales que veían la luz, y la consecuente salvación para nuestras repúblicas, en Europa, sino, también, a todo fundamentalismo que negaba los frutos del contacto con Occidente. Me refiero a movimientos indigenistas de esos años.

${ }^{9}$ Ver Antonio Cornejo Polar, A. (Sobre literatura y crítica latinoamericana 36). 
particularidades, abogue por una totalidad contradictoria ${ }^{10}$. La clave se halla en el reconocimiento de la diferencia, en empezar a despojarse de esos esencialismos que nos hablan de identidades y morales innatas, para reivindicar la otredad. Con palabras de Guillermo Mariaca Iturri, la idea es
encontrar una red de estrategias críticas, todavía débiles pero incitantes, que puedan dar razón de ese abigarrado corpus y ensayar perspectivas desde las cuales la identidad no sea un rasero que hace uniforme lo que es multívoco sino - al contrario - una instancia abierta y porosa, oscilante entre un centro escurridizo y sus límites marginales, también borrosos, y que sea lo suficientemente osada como para reconocer que la identidad es mucho más que un concepto claustral, hecho de exclusiones, es un espacio abierto donde yo y el otro tienen la opción de una gozosa (pero también dramática) plenitud (32) ${ }^{11}$.

Está claro que la tarea primera es reconocer nuestra propia identidad, que no es una abstracción metafísica, ni una actitud sicológica: es una realidad colectiva, hecha de todos, pero donde esos todos participen con su singular diferencia. América Latina posee una identidad de este tipo porque en ella convive una sociedad que sobre sus diferencias ha sido capaz de construir una cultura que le es propia. Pero no basta con que exista esta realidad heterogénea; se hace indispensable defender esa identidad con el propósito de construir la nación, o la supranación latinoamericana. Defenderla porque, al ser móvil y al estar siendo bombardeada por todo tipo de intereses, no es improbable que se debilite. Primera cuestión. Lo otro tiene que ver, según nuestro punto de vista, con la autoafirmación como latinoamericanos. La diversidad cultural potencia a las naciones, le otorga un espesor identitario que la hace menos vulnerable - y por tanto más resistente - frente a los influjos y contactos foráneos. Sin embargo, para que esta diversidad adquiera vigencia y valor requiere, de parte de los que la componen, una autodeterminación que no deje fuera sus rasgos singulares y que, a su vez, integre al colectivo, desde esa diferencia. En otras palabras, si no sabemos quiénes somos, difícilmente nos podremos sentir parte de una nación, de una patria, de una región. En la medida que nos construyamos a nosotros mismos, nos estamos también construyendo en y con la comunidad con la que nos identificamos y, por cierto, nos diferenciamos. Nos hacemos pues en la diferencia. Somos así porque no somos así. La historia personal, familiar, comunitaria, juegan aquí un rol esencial. Ese es el sentido que se le debe dar a la identidad, una instancia "abierta" y "porosa" que permita construirnos en plenitud. Sin este ingrediente, el proyecto martiano no funciona. Porque un principio fundamental al que el cubano apela es al hacerse desde uno mismo. Esto exige usar nuestros propios métodos. ¿Cómo se hace alguien? Asumiendo su historia personal, reconociéndose parte de un grupo mayor,

\footnotetext{
10 "La literatura peruana: totalidad contradictoria", es el título de una ponencia que Antonio Cornejo Polar dictara con motivo de su incorporación a la Academia Peruana de la Lengua, en mayo de 1982, con sucesivas publicaciones posteriores (Cornejo Polar, Sobre literatura, 48).

${ }^{11}$ Citado del prólogo a cargo de Antonio Comejo Polar.
} 
integrándose sin negarse y proponiendo instancias más amplias de participación. No nos hacemos imitando ni recogiendo otras identidades, creyendo que lo suyo es algo ya hecho a priori, metafísicamente. Insistamos: nos hacemos solo en y con el otro, histórica, social, colectivamente. Pero esto no ha podido darse. Lo que para Cornejo Polar se convierte en un trauma que es producto del desajuste, entre una identidad que aparenta ser la nuestra, pero por su carácter monolítico e invariable no puede serlo, y la aceptación —y el imperativo - de que, efectivamente, la nuestra no puede ser sino algo que se construya relacionalmente. "El sujeto, individual o colectivo, no se construye en y para sí; se hace, casi literalmente, en relación con otros sujetos, pero también (y decisivamente) por y en su relación con el mundo". Estamos cruzados por una falta "ante el mundo y ante nosotros mismos, al descubrir que carecemos de una identidad clara y distinta" (Cornejo Polar, Escribir en el aire, 22). Aunque usamos esa falta no como un vacío que por necesidad haya que llenar, a fin de asimilarnos a la imagen del paradigma moderno impuesto por Occidente, sino, al contrario, como dispositivo para reafirmar nuestra diferencia, y desde ella construir nuestra propia y particular identidad latinoamericana. Luego, si llevamos esto a la lectura de "Nuestra América", lo que viene es la figura que aparece de todo esto, y el rol que le compete en el escenario martiano. Aparece un sujeto nuevo. Estamos frente a la instalación de un ser latinoamericano que debe ser capaz de "reequilibrar los factores del proceso de modernización y frenar el expansionismo norteamericano" (Rojo, Las armas de las letras, 114) ${ }^{12}$.

Ahora bien, sin desvirtuarnos de lo que venimos diciendo vamos a hacer un giro enfático de un tema que resulta crucial para entender el problema de fondo que aqueja a esta región, y que lamentablemente sigue presente en nuestra convivencia - en Chile quizá más que en otras partes-, vamos a detenernos en esta parte del sujeto despreciado en tanto cuerpo violentado.

La unidad de la que hablamos arriba no se presenta, para Julio Ramos, como una totalidad desde siempre constituida. Esto porque ahí "el ser americano se presenta como efecto de la violenta interacción de fragmentos que tienden, anárquicamente, a la dispersión" (290).

Éramos una visión, con el pecho de atleta, las manos de petimetre y la frente de niño. Éramos una máscara, con los calzones de Inglaterra, el chaleco parisiense, el chaquetón de Norteamérica y la montera de España. El indio, mudo, nos daba vueltas alrededor, y se iba al monte, a la cumbre del monte, a bautizar sus hijos. El negro, oteado, cantaba en la noche la música de su corazón, solo y desconocido, entre las olas y las fieras. El campesino, el creador, se revolvía, ciego de indignación, contra la ciudad desdeñosa, contra su criatura (Martí, 484-485).

${ }^{12}$ Citado en Ossandón C. (73). 
Pero más que una unidad orgánica, ese cuerpo, el de la madre América, ha sido "descoyuntado" y "descompuesto". Armado de restos de códigos, de fragmentos incongruentes de tradiciones en pugna, ese cuerpo es el producto de una violencia histórica, del desplazamiento de los "orígenes confusos y manchados de sangre". El discurso martiano se sitúa, así, según Ramos, ante la fragmentación e intenta condensar lo disperso. De aquí se desprende la ambigüedad de la teleología martiana: la historia que no es vista como el devenir armonioso de la perfectividad futura, sino más bien como el proceso de luchas continuas, de un "pasado sofocante". El devenir implica descomponer la totalidad "de cuyo cuerpo orgánico y originario solo quedan restos que deben ser rearticulados". Para Martí este ejercicio ordenador, "hermanador", era doblemente necesario: "garantizaría la consolidación del buen gobierno ya que contribuiría a dominar el parricidio [entre] los 'tigres de adentro', además posibilitaría la defensa de la familia recompuesta contra la amenaza de la intervención extranjera, el "tigre de afuera" [sus marcas]. Aquí está el ser latinoamericano: entre la dialéctica del adentro/afuera, en el doble movimiento de la homogeneización del interior, "la casa de nuestra América" y la exclusión de los "otros", sin duda poderosos, cuya amenaza en todo caso posibilita y hace indispensable la consolidación del interior. Pero en Nuestra América, agrega el puertorriqueño, "ellos" no es solo pronombre del capital, de la modernidad extranjera. El "nos-otros", según el propio Martí, también estaba lleno de "tigres otros" que impedían la coherencia del ser latinoamericano. ¿Qué tipos de fuerzas generaban la fragmentación interior? (Ramos, 290-291).

Las fuerzas, dice Ramos, de las ideas del progresismo positivista de fin de siglo. Agrega que Nuestra América emerge precisamente en una época de circulación y dominio de representaciones de América Latina como cuerpo enfermo, contaminado por la impureza racial, por las sobrevivencias de etnias y culturas tradicionales supuestamente destinadas a desaparecer en el devenir del progreso y la modernidad. América Latina es un cuerpo herido, el Pueblo enfermo (1909), de Alcides Arguedas, que ya no mejora, está corrompido y ante esto no queda otra que exterminarlo. Esa es la clave del discurso positivista, que ve en la mancillada tradición indígena una rémora para el progreso. Pero un discurso que no queda ahí: es el mismo argumento que luego se resignifica y cobra presencia real y material en nuestra historia contemporánea, y sobre el que las dictaduras exterminarán los cuerpos de ese otro (opositor, subversivo, distinto). Un cuerpo que debe desaparecer. Para eso se secuestra, se destierra, se tortura, se mata, o, por último, en versión actual, se excluye. Por eso, creemos, que Ramos no subestima el acercamiento que hace Martí a las raíces de ese cuerpo aplastado por la modernización, ya que las ruinas denunciarán ahora al "tigre de adentro". El cuerpo destrozado revelará que su victimario no es solo el "tigre de afuera" sino que se halla en ese "nos-otros" que esconde "otro" que es el del discurso civilizador, la causa misma de su enfermedad (Ramos, 297). 
Visto así el caos entonces no viene de la "barbarie", de la carencia de modernidad, de la no civilización. "Los hombres naturales han vencido a los letrados artificiales. El mestizo autóctono ha vencido al criollo exótico. No hay batalla entre la civilización y la barbarie, sino entre la falsa erudición y la naturaleza" (Martí, 482). La descomposición de América - agrega Ramos - es producida por la exclusión de las culturas tradicionales del espacio de la representación política. De ahí que "Nuestra América" proponga la construcción de un "nosotros" hecho justamente con la materia excluida por los discursos —y los Estados- modernizadores: el "indio mudo", el "negro oteado", el campesino marginado por la ciudad desdeñosa. Porque si el "hombre natural" no era incluido en el proyecto del ser nacional, en el espacio del buen gobierno, se lo sacude y gobierna (Ramos, 298).

Pero retomemos la tarea de la reconstrucción del sujeto nacional. Habíamos dicho que Rojo despliega tres formas o "esfuerzos" para la conformación de una autoconciencia a favor de la unidad regional. La primera implicaba reconocer el desajuste de origen que se da entre las estructuras del Estado y su contenido que es la nación natural. Mas también en este sentido surge la necesidad de la reapropiación de sí mismo que no es otra cosa que crear un sujeto nacional, desde este "hombre natural", excluido a partir de la "inclusión".

Toca ver la segunda de estas "estaciones obligadas de este esfuerzo de autoconocimiento": la libertad, la única que hará posible que los hombres desplieguen su potencial del ser. "Además del ser, del saber y del querer ser", es preciso que existan condiciones históricas que permitan [...] la transformación de la naturaleza verdadera en conducta eficaz" (Rojo, Clásicos latinoamericanos, 220226). Es todo un contexto el que se requiere para que el hombre vaya en busca de su conversión a sujeto nacional. Y para eso requiere asumir la historia. Si es libre sabrá incorporarla y transformarla en esa conducta eficaz. Debe ir hacia atrás para venirse haciendo y alcanzar el ser. Y qué arrastra. Una historia desastrosa pero suya. Pero también un capital por revelar. "Con los oprimidos había que hacer causa común para afianzar el sistema opuesto a los intereses y hábitos de mando de los opresores" (Martí, 484). Compartimos con Rojo la potencia de esta frase. Entre otras cosas porque aparte de instalar la dicotomía oprimidos/opresores que otorga una cuota más de comprensión sobre el desprecio del hombre natural, hallamos que junto al sentido de solidaridad que envuelven "había" y "causa común", hay una carga reveladoramente positiva en "afianzar el sistema opuesto". Se afianza algo que ya está erguido, para mantenerlo así o para alzarlo más, no lo caído, eso se levanta. Lo que implica una resistencia previa e inherente del oprimido, es decir, una opresión que no se ha mantenido pasiva; ha buscado las formas de zafarse, ha tenido la voluntad de hacerlo, pero su resistencia y su fuerza no han sido suficientes porque no ha sido libre, no ha reconocido aún en libertad su condición de oprimido, por tanto no se le ha hecho manifiesto aún el capital histórico que guarda, ha contado solo con la forma y no con el "espíritu" necesario. Esto nos conecta con aquello que señala De Certeau 
que las estrategias dominantes del sistema productor contarán siempre con elementos que jugarán en su contra, que no se reducen a ella: las tácticas (De Certeau, 26 y ss.). El "sistema opuesto" es una instancia de poder no creada desde el opresor sino desde el mismo oprimido. Se ha venido construyendo entonces un sistema de oposición cuyo sujeto es acorde con su opuesto. Se ha creado una cultura de la resistencia. Podemos decir acaso que en nuestra historia mientras más opresión no más insumisión, mientras más fuerza no más debilitamiento, mientras más desprecio no más inferioridad. Queremos creer que el oprimido capitaliza su condición — como dice De Certeau - en ardid con el que va subvirtiendo, subrepticiamente, el mando opresor. Esta tesis esperanzadora y desiderativa para nosotros es clave en el propósito nuestroamericanista, porque es la dinámica propia del mundo popular.

Termina Rojo esta revisión suya sobre el autoconocimiento, con el tercer esfuerzo, cual es el de la crítica que hace Martí del "exclusionismo oligárquico y su insistencia en la necesidad de una cultura más abarcadora y solidaria" (Clásicos latinoamericanos, 227). En el fondo es el reclamo por una democracia que por ochenta años ha venido siendo aplazada, quedando hipotecada en unos pocos. Eso, ahora, ya no podía esperar. Debía llevarse a cabo porque están las condiciones y no por no haber estado se justifica una historia de exclusiones primero de sujetos y luego de ciudadanos. Como sea, el sujeto está libre para asumir el buen gobierno. De lo contrario, recuérdese, que ya no es solo la oligarquía; ahora es el mal mayor, el gigante del capitalismo norteamericano. Entonces de lo que se trata ahora es de crear. Y la manera de hacerlo para Martí, dice Rojo, es por la vía del conocimiento mutuo. $\mathrm{O}$ sea, ese segundo nivel de la unidad en conciencia. Conocerse pero también conocer al vecino y conociendo al vecino conociéndose. Otra vez la idea de la identidad relacional. Un proceso que parte en uno, luego la familia, después los vecinos, la nación y la región, y el mundo. Aquí recién comienza el proyecto humanista universal martiano, en la Sociedad mundial solidaria.

\author{
Universidad de São Paulo* \\ Departamento de Teoria Literária e Literatura Comparada \\ Av. Professor Luciano Gualberto, 403 \\ Cidade Universitária - Butantã CEP: 05508-010 \\ São Paulo (Brasil) \\ marcochandia@gmail.com
}

\title{
OBRAS CITADAS
}

Cornejo Polar, A. Sobre literatura y crítica latinoamericana. Caracas: Universidad Central de Venezuela, 1982.

- Escribir en el aire. Ensayo sobre la heterogeneidad sociocultural en las literaturas andinas [1994]. Lima: Horizonte, 2003. 
De Certeau, M. La invención de lo cotidiano. 1 Artes de hacer [1980]. México: Universidad Iberoamericana, 2000.

Henríquez Ureña, P. La utopía de América [1925], pról. R. Gutiérrez Girardot, comp., y cronología Á. Rama y R. Gutiérrez Girardot. Caracas: Ayacucho, 1978.

Mariaca Iturri, G. El poder de la palabra: ensayos sobre la modernidad de la crítica literaria hispanoamericana. La Habana: Casa de las Américas, 1993.

Martí, J. Obras escogidas en tres tomos. La Habana: Ciencias sociales, 2002.

Ossandón C. "Nuestra América", en: Boletín de Filosofia, № 9 (1997-1998), p. 73.

Ramos, J. Desencuentros de la modernidad en América Latina. Literatura y política en el siglo XIX [1989]. Fondo de Cultura Económica. México, 2003.

Rojo, G. "Martí y la identidad", en: Las armas de las letras. Ensayos neoarielistas. Santiago de Chile: LOM, 2008, 101-116

Clásicos latinoamericanos. Para una relectura del canon. Vol. I: El siglo XIX. Santiago de Chile: LOM, 2011

Salazar, G. y J. Pinto. Historia contemporánea de Chile I. Estado, legitimidad, ciudadanía. Santiago de Chile: LOM, 1999.

Subercaseaux, B. Chile, ¿un país moderno? Santiago de Chile: Ediciones B., 1996. 